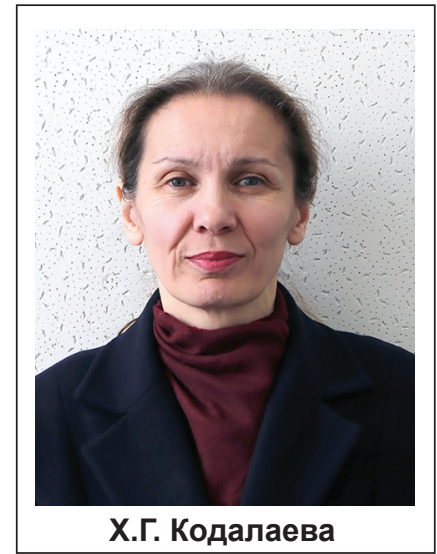

\title{
ГРУЗИНО-ОСЕТИНСКИЙ КОНФЛИКТ 1989-1992 Гг. В ОСВЕЩЕНИИ СМИ РСО-А
}

\author{
Х.Г. Кодалаева*
}

\begin{abstract}
Аннотация. В статье рассматривается грузино-осетинский конфрликт 1989-1992 годов в контексте эволюционных процессов в печатных СМИ PCO-А. В рамках указанного периода анализируются наиболее содержательные публикации на страницах республиканской прессы («Северная Осетия», «Рæстдзинад», "Слово»), где показаны причины возникновения и сущность преступных действий национал-экстремистских кругов Грузии.

Ключевые слова: грузино-осетинский консрликт, эволюционные процессы в печатных СМИ, этнополитические процессы, инфрормационная блокада, религиозный фрактор, североосетинская печать.
\end{abstract}

Безумная либерализация государственно-политических отношений в постсоветское время обусловила оживление этнополитических процессов на пространстве бывшего союзного государства. «Этнополитический ренессанс», в свою очередь, способствовал росту среди народов некогда необъятной страны не только национального самосознания, но и сепаратизма и агрессивного национализма. В конце 1980-х - начале 1990-х годов XX века этнополитические процессы приобрели самые разнообразные формы. В различных концах страны создавались национально-культурные общества, политические движения, ассоциации, землячества. Созывались конгрессы, симпозиумы, съезды народов для решения многообразных задач - политических, экономических, социальных, лингвистических - призванных, естественно, для сохранения этнокультурной самобытности, повышения статуса титульных народов. Национальные автономии превращались в самостоятельные республики в составе России, Грузии и Азербайджана. Все эти процессы шли под лозунгами национального возрождения и апелляции к религии как источнику национальных ценностей. В то же время широкое распространение получили межэтнические и внутриэтнические конфлликты на Северном Кавказе (Дагестан, Чечено-Ингушетия, Карачаево-Черкесия, Адыгея, Кабардино-Балкария, Северная Осетия-Алания), в Закавказье (Абхазия, Южная Осетия, Нагорный Карабах) и Поволжье (Татарстан, Башкортостан).

Острый характер приобрела эта борьба и внутри республик между местными органами власти и национально-политическими движениями по поводу дальнейшего государственного устройства. Все эти этнополитические процессы проходили на фоне заметного роста активности националистических движений и фундаменталистских организаций, которые все в большей мере проявляли себя как силы, оказывающие ощутимое воздействие на этнополитическую обстановку в и без того ослабленной стране. Значительную роль в этнополитических процессах сыграли новые для Северного и Южного Кавказа радикальные, исламистские движения, учения и националистические партии крайнего толка, распространившиеся в обозначенный период (конец 80-х - начало 90-х гг. XX в.). Они в значительной мере усиливали негативные тенденции этнонациональных отношений, что создавало угрозу дальнейшего роста сепаратистских настроений и обусловленных ими этнополитических конфлликтов, способных привести теперь уже Россию и другие бывшие союзные республики к развалу, как ранее СССР.

Влияние негативных фракторов на этнополитические процессы не только породило реальную угрозу перспективе мирного реформирования гражданских обществ в постсоветском пространстве, но стало помехой сохранению политической стабильности и территориальной целостности страны. Тем не менее до сих пор, по прошествии четверти века, не дано однозначного ответа на вопрос об истоках и природе этих феноменов, их влиянии на этнополитические процессы. К огромному сожалению, этим событиям не дана и политическая оценка. Если собственно этнополитические процессы в Северной и Южной Осетии стали предметом пристального интереса специалистов, то их освещение и интерпретация в средствах массовой информации в РСО-А, а также место СМИ в этих событиях остаются практически неисследованными. Между тем СМИ как четвертая власть тесно связаны с этносом и межэтническими процессами и выполняют в них как интегрирующую, так и дезинтегрирующую функции, сплачивая одни этнические группы и разделяя другие на основе деструктивных публикаций и низвержения социальной доктрины. В Осетии насчитывается более 60 этносов, традиционно и нетрадиционно исповедующих самые различные вероучения.

Кодалаева Хансиат Герсановна - зав. кафедрой журналистики Юго-Осетинского государственного университета Цхинвал, Республика Южная Осетия. 
Взаимосвязь этнического и информационного факторов создает в случае возникновения какихлибо конфликтов возможность для смягчения, предотвращения этноконфессиональных столкновений. Одновременно масс-медиа таят в себе возможности углубления этноконфессиональных коллизий, разжигания экстремизма под национальными лозунгами.

Изучение взаимодействия СМИ и национальных (межнациональных) отношений очень важно для понимания состояния и перспектив развития любого постконфликтного общества, выработки национальной и информационной политики. Именно эти обстоятельства обусловливают актуальность избранной для исследования проблемы. Некоторые проблемные вопросы взаимосвязи этнической истории и ее освещения в средствах массовой информации в той или иной степени ставятся и решаются в работах российских и зарубежных ученых. Однако, к сожалению, они до сих пор не подвергнуты комплексному, систематическому исследованию. В данной статье мы использовали богатый фактический материал по проблемам освещения грузино-осетинского конфликта в североосетинской прессе. Такие отечественные и национальные ученые и журналисты, как В. Авксентьев, И. Бабкин, И. Санакоев, Ф. Сизый, Т. Очирова, Д. Джиошвили, Е. Глебова, А. Пральников, В. Астров и другие высказывались в пользу незамедлительной остановки кровавой бойни в Южной Осетии [1-8]. Определение причин непостижимого варварства на пороге XXI века, творимого в Южной Осетии, дает ключ к пониманию подлинных истоков кровавого конфликта между двумя соседними народами.

Ценные теоретические и методологические положения по исследуемой тематике содержатся в трудах известных осетинских историков и политологов - таких как В. Дзидзоев, К. Дзугаев, В. Абаев, С. Дзарасов, Ж. Кочиева, Х. Джикаева, Б. Олейник, Г. Немченко, К. Цаголов и другие [9-19]. Они анализируют разные аспекты возникновения конфликта, истоки и фракторы эволюции грузиноосетинского конфликта, влияние исследований кровавых событий на духовную и общественнополитическую жизнь в пределах Большого Кавказа. И этим они внесли заметный вклад в изучение истории зарождения и усугубления конфликта, становление и развитие националистической доктрины грузинского национал-экстремизма. Однако ряд наиболее острых и актуальных для современного осетинского общества проблем, связанных с освещением грузино-осетинского конфрликта 1989-1992 годов прошлого века на страницах североосетинской печати («Мах дуг», «Дарьял», «Северная Осетия», «Растдзинад», «Слово») и влиянием СМИ на этнополитические процессы, остаются недостаточно разработанными. В частности, слабо исследованы многочисленные публикации в главных республиканских газетах, анализировавшие истоки и причины грузинского сепаратизма, национализма, экстремизма и их связь с зарубежными антироссийскими организациями.

Нельзя не отметить, что неоднозначность выводов и оценок зачастую объективно обусловлена сложностью и противоречивостью реальной обстановки и, соответственно, многоаспектностью роли информационной войны в социально-политических и духовно-нравственных процессах внутри Осетии и вокруг нее. Исследовательская недосказанность и предвзятость грузинской стороны являются проявлением субъективизма и тенденциозности наших оппонентов. Именно такими некомпетентными авторами грузино-осетинский конфликт начала девяностых прошлого столетия характеризуется в категорических формулировках. Более того, во многих работах научный (понятийный) аппарат, связанный с грузино-осетинской тематикой, не получал сущностной обоснованности и методологической четкости. Так, до сих пор не дана политическая оценка тех кровавых событий, да и само понятие «грузинский национал-экстремизм» не имеет общепризнанного, однозначного определения. Вместо этого дается перечень обычных характеристик, за которыми теряется зловещая сущность данного понятия. Столь же противоречивые суждения наличествуют в научной литературе и СМИ о генезисе и характере эволюции грузино-осетинского конфликта, который на западе имеет совсем другую «трактовку» и давно превратился в жупел русофобии и осетинофобии для запугивания европейского обывателя: «Россия оккупировала часть Грузии», «Россия аннексирует Южную Осетию» и т. д. Много разночтений и в определении понятий «грузино-осетинский конфрликт», «независимая Южная Осетия», ставших своеобразным ярлыком, который навешивается практически на все процессы, происходящие внутри и вокруг молодого независимого государства.

Исходя из актуальности, научной и практической значимости изучения указанных проблем объектом исследования стало освещение названных вопросов на страницах североосетинской печати («Социалистическая Осетия», «Растдзинад», «Слово», «Мах дуг», «Дарьял» и т. д.) как реальный фрактор этнополитических процессов в Кавказском регионе. Представляют интерес конкретные формы идеологии и практики национал-экстремистских движений с точки зрения их влияния на этнополитические процессы в Северной и Южной Осетии. Целью исследования является выявление характера, направлений и степени влияния местной печати на состояние и тенденции развития этнополитических процессов в указанный период. В исследовании по-новому поставлены и проанализированы информационно-методологические вопросы, касающиеся взаимодействия национального, этического и политического фракторов.

С одной стороны, вроде бы обилие материала 
давало простор при подборе фактов для анализа конкретных статей, очерков, заметок, интервью, аналитических обзоров. С другой - возникали проблемы с определением критериев такого подбора; многие прозвучавшие темы не вписывались в общую канву исследования и поэтому оказались за ее рамками. Это было связано с тем, что еще в конце 80-х годов только что прошлого века появление югоосетинской тематики в североосетинской и центральной прессе было событием экстраординарным, воспринималось как информационная сенсация, не говоря уже о единичных фактах внимания к событиям в Южной Осетии со стороны зарубежных СМИ. Однако ситуация резко изменилась в 1991-1992 годах, с началом вооруженной агрессии против мирного населения Южной Осетии [20]. Временами РЮО для некоторых средств массовой информации даже ставилась основной темой.

За те полтора года войны Южную Осетию посетило (по данным Госкомитета информации и печати РЮО) 1800 журналистов более чем из 50 стран [4]. Значительную часть из них составляли электронные СМИ, но представителей прессы тоже было немало. По свидетельству председателя правления Союза журналистов РЮО Б. Харебова, «в мире не осталось ни одной более-менее солидной газеты или политического журнала, информационного агентства, которые не направили в Южную Осетию своих корреспондентов, порой - лучших. Безусловно, они работали по-разному, преследовали расхожие цели, рассматривали ситуацию в регионе под различными углами зрения, но, в целом, основное свое предназначение - дать максимальную информацию о том, что происходит в РЮО и вокруг нее - они выполнили. По известным причинам, не весь материал, наработанный журналистикой во время кровавых событий в Южной Осетии, вернулся в регион в виде публикаций в самых разных жанрах, но большинство из них стали достоянием местной, российской и мировой общественности. Даже лидеры грузинских национал-экстремистов были вынуждены признать, что «информационную войну 1989-1991 гг. они проиграли» [4].

Свою лепту в общее дело - справедливое освещение грузино-осетинского конфоликта - внесла и североосетинская печать. Особенно в этом преуспели республиканские газеты «Северная Осетия», «Растдзинад» и «Слово». Литературнохудожественный журнал «Мах дуг» выходил редко и занимал пассивную позицию. Что касается «Дарьяла», то он начал издаваться только в 1991 году, поэтому не мог активно участвовать в этом информационном процессе. Главные республиканские газеты ввели постоянную рубрику «К событиям в Южной Осетии» и, как правило, печатали соответствующую информацию на первой странице (иногда под логотипом газеты, иногда в нижнем правом или левом углу). Корреспонденты названных из- даний регулярно выезжали в Южную Осетию и не понаслышке знали ситуацию в зоне конфликта. На страницах «Северной Осетии» и «Растдзинад» во всю мощь звучал и голос интеллигенции: писатели, ученые, актеры, деятели искусства, выполняя свой гражданский долг, распространял правду о трагических событиях в Южной Осетии. А когда у североосетинской печати не хватало собственных материалов (особенно в зимний период, когда изза схода лавин прекращалось сообщение между Севером и Югом Осетии), то газеты перепечатывали статьи и корреспонденции из центральных изданий.

«Растдзинад» и «Северная Осетия» часто публиковали обращения общественных организаций [22-25] и частных лиц [26-27], которые с возмущением писали о преступлениях грузинской хунты и требовали немедленно остановить эту бойню, убийство невинных людей. В декабре 1991 года во Владикавказе состоялся Чрезвычайный съезд осетинского народа. Североосетинская печать на первых страницах печатает декларации, резолюции, обращения этого общенационального форума с осуждением агрессора и призывом немедленно остановить преступления против целого народа [28-32]. Обращения один за другим поступали к руководителям Союзного государства (М.С. Горбачеву) и РФ (Б.Н. Ельцину) [33]. Достоянием читателей становились и ответы и обращения этих руководителей. Газеты вынуждены были констатировать, что эфрфективность данных документов была чрезвычайно низка. Причиной такого положения печатные СМИ чаще всего называли тот объективный фракт, что СССР находился в полуразваленном состоянии, а РФ еще твердо не встала на ноги.

Поэтому публикации североосетинской печати играли важную роль, так как разоблачали политический экстремизм грузинских националистических кругов, волею случая оказавшихся у власти. Эти материалы убедительно доказали, что побудительной причиной, поводом для проявления политического экстремизма стали острые противоречия в социальной сфере (читай - социальный экстремизм), в сорере межэтнических отношений (этнический экстремизм: Грузия - для грузин), в конфессиональной сфере (религиозный экстремизм: чего стоят заявления грузинского патриарха Илии II) и т. д. При этом, политический экстремизм властей Грузии не получил своевременной оценки, не подвергался объективной критике, зашел достаточно далеко и довел противостояние от острого социального конфликта до вооруженной агрессии (гражданской войны) против своих же граждан.

В этих условиях североосетинская печать продолжала по мере возможности прорывать информационную блокаду, объясняя цивилизованному миру, как разжигание ненависти между грузинами, осетинами и абхазами привело сначала к вооруженным конфликтам, а потом к актам геноцида 
против автономных образований и национальных меньшинств. Журналисты республиканских газет «Северная Осетия» и «Растдзинад» систематически публиковали информационные и аналитические материалы с позиций защиты политических прав и национальных интересов своих южных братьев. По существу, выполняя роль военкоров, они разъясняли, как националистические круги грузинской верхушки, заявляя об исключительности своего народа, отказывали другим народам и этническим группам даже в самом малом - в праве говорить на родном языке и иметь свою автономию. С одной стороны, североосетинская печать не допускала резких выступлений беженцев против тех грузин, которые проживали на территории РСО-А. И в том, что на севере Осетии сохранилась 10-тысячная грузинская община, несомненно, была заслуга и местных изданий. С другой убеждала своих читателей в том, какую пагубную роль несет в себе утверждение кровавого господства одного народа над другим. Особенно если это происходит на Кавказе.

Североосетинская периодическая печать не обошла стороной и религиозный экстремизм в исполнении грузинского патриархата и лично главы Грузинской Православной церкви. Вот что писал о нем президент Ассоциации творческой и научной интеллигенции «Ир» А.А. Дзантиев: «Нынешний духовный отец и наставник грузинского народа утверждает, что беззаветно преданные ему отряды боевиков жестоко карают иноплеменников во имя самой высокой и благородной цели - во имя демократии, из любви к свободе и независимости своей родины - Грузии. Какая дикость, какое непостижимое варварство на пороге XXI века! Да есть ли цель, хотя бы мало-мальски оправдывающая посягательства насвятая святых - человеческую жизнь?!» [34; 22-25]. Развивая свою мысль на основе тщательного анализа ситуации, известный общественный деятель Осетии пришел к твердому убеждению о том, что «гипертрофрированное самомнение новоявленного отца нации приятно щекочет перспектива находиться в одной шеренге с самыми оголтелыми фашиствующими диктаторами и властной, «железной» рукой проводить в жизнь их имперскую доктрину» [34; 22-25]. И приводит в качестве примера иезуитские слова А. Пиночета: «Демократию необходимо время от времени купать в крови для того, чтобы она продолжала оставаться демократией». Сравнив между собой слова фашиствующих деятелей, А. Дзантиев дал закономерную оценку их смысловой идентичности: «Невежливость, дикость, грубый диктат власти, замешанные на крутом национализме, вот подлинные истоки того варварства и человеконенавистничества, которыми ныне охвачена Южная Осетия и откуда пожар в любую минуту готов перекинуться на Абхазию, Аджарию, на всю Грузию» [34; 22-25]. От себя добавим: так оно и случилось впоследствии.
Употребляя словосочетание «религиозный экстремизм», журналисты Северной Осетии единогласно пришли к выводу, что оно является проявлением нетерпимости к представителям иных народов и конфессий, жестокого противоборства в рамках одного многонационального региона. Поэтому отсюда вытекает адекватное понимание сущности «религиозного экстремизма», причин его возникновения, а также выработка научнообоснованных рекомендаций для СМИ по противодействию этому опасному социальному злу. Важным шагом североосетинской печати было и объяснение религиозного экстремизма путем выявления его социальных и политических истоков и специфических черт и особенностей идеологии и практики грузинской церкви, в которой он наиболее ярко проявился в последние три десятилетия. Как подметили ведущие журналисты Северной Осетии, принципиальной разницы в религиозноэкстремистских проявлениях в различных конфессиях не существует: все они, апеллируя к Всевышнему, пытаются реализовать радикальными методами свои земные националистические интересы. Условно грузинский религиозно-политический экстремизм они определили как использование религиозного фактора (религиозного лозунга) для реализации политических интересов методами насилия, игнорирующими гражданское, государственное и международное право. Религия в таком случае использовалась и сейчас используется для идейного обоснования экстремистской политики и является средством объединения, мобилизации и организации политических экстремистов. Корни грузинского экстремизма, по их мнению, заключены в причинах комплексного характера, формировавшихся в течение десятилетий и целых веков. Они имеют прямое отношение к региональным конфликтам, внутренним проблемам и дефициту демократических настроений. Ввиду этого проблемы религиозного экстремизма они не отделяют от решения политических, межэтнических и социальных проблем.

Таким образом, авторитетные представители североосетинской печатной прессы считают, что грузинский этнонациональный, политический и религиозный экстремизм является следствием длительной неразрешенности, консервации давно назревших межнациональных проблем, пережитков «княжеского» высокомерия и неуважения к национальным меньшинствам, несправедливости и насилия, допущенных в отношении южных осетин, абхазов, армян, азербайджанцев, греков, евреев и месхетинских турков, которые до сих пор пребывают в изгнании со своей исторической родины. В свете сказанного заметим, что среди российских богословов и ученых понятие «грузинский экстремизм» (политический, национальный, религиозный, социальный) не получило еще должного внимания. Грузинские фундаменталисты, националисты и даже представители правящих кругов 
и парламентариев трактуют его однозначно - как борьбу за свободу, демократию и независимость Грузии. Как будто другим народам эти блага цивилизации не рекомендованы. Не получив должного осуждения, грузинские националисты (где открыто, а где скрытно) продолжают рассматривать вооруженную агрессию как единственное средство решения межнациональных проблем. В условиях современной Грузии даже проблема религии перестала быть чисто богословской и приобрела ярко выраженный политический характер. Видимо, поэтому она не получила до сих пор серьезного обсуждения на богословном уровне в православном мире применительно к событиям в Южной Осетии и Абхазии. В то же время радикально на- строенные грузинские богословы во главе со своим «блаженнейшим» патриархом внутри страны и за рубежом продолжают трактовать военный конфликт в Южной Осетии в категориях реванша и возмездия. Прав профессор В.Д. Дзидзоев, который подчеркивает: «Сложное положение сохраняется в Республике Южная Осетия, независимость которой признана РФ 26 августа 2008 г., а затем рядом других государств. Тбилисские власти продолжают вынашивать планы по насильственному возвращению Южной Осетии и Абхазии в состав Республики Грузия. Это создает огромные проблемы не только для Южной Осетии, но и для Северной Осетии, в целом для Российской Федерации» [9-19].

\section{ЛИТЕРАТУРА}

1. Авксентьев В.А. Этническая конфлликтология: в поисках научной парадигмы. - Ставрополь, 2001.

2. Бабкин И.О. Феномен этнического сепаратизма: Автореф. дисс. ... канд. полит, наук. - Ставрополь, 2001.

3. Санакоев И.Б. Истоки и фракторы эволюции грузино-осе тинского конфрликта (1989-1992 гг.). - Владикавказ: Издательско-полиграфрическое предприятие им. В.А. Гассиева, 2004. 160 c.

4. Сизый Ф. Дом окнами на войну // Комсомольская правда. 1991. 31 января.

5. Очирова Т., Джиошвили Д. Братоубийство // Литературная Россия. 1991. 8 фревраля.

6. Глебова Е. Шальные пули снайперов // Московский комсомолец. 1991. 15-16 фревраля.

7. Пральников А. Цхинвали с Бейрутским акцентом // Meгаполис-экспресс. 1991. 31 января.

8. Астров Виктор. Ночь в Цхинвали // Мегаполис-континент. 1991. № 8.Февраль-март.

9. Дзидзоев В.Д. Осетия в эпоху больших потрясений и перемен (исторический и политико-правовой анализ постсоветской истории). - Владикавказ, 2010.

10. Дзидзоев В.Д. Проблемы советского национально-государственного строительства в Осетии и постсовет ские итоги (политико-правовой анализ). - Владикавказ 2011.

11. Дзидзоев В.Д. Борьба югоосетинского народа за наци ональное самоопределение. 1917-1990 ге. - Владикавказ 2011.

12. Дзидзоев В.Д., Дзугаев К.Г. Южная Осетия в ретроспективе грузино-осетинских отношений. - Цхинвал, 2007.

13. Абаев В.И. Трагедия Южной Осетии: беспредел геноцида. - Цхинвал,2007.

14. Дзарасов С. Анатомия беды // Голос (Москва). 1991. № 15. Апрель.

15. Чочиева Ж. Большой кавказский дом //Завтра. 1997. № 34. C. 3 .

16. Джикаев Х. Позвольте возразить. ДИКость: [Haس ответ вице-президенту США Дику Чейни] // Пульс Осетии. 2006. № 33. Август.

17. Цаголов Ким. Национальный мещанин с ружьем // Рабочая трибуна (Москва). 1991. 12 марта.

18. Олейник Б. Этот конфрликт опаляет всю страну: [Беседа после возвращения из Южной Осетии] // Советская Россия. 1991. 26 февраля.
19. Немченко Г. Цветы зла: [Слово писателя] // Правда. 1991. 16 апреля.

20. Южная Осетия глазами журналистов (1991-1992) / Сост. Алексей Маргиев.- Цхинвал: Издательство «Ирыстон», 2001. 344 C.

21. Южная Осетия глазами журналистов (1991-1992) / Сост. Алексей Маргиев. Предисловие Б. Харебова. - Цхинвал: Издательство «Ирыстон», 2001.

22. Президенту Союза Советских Социалистических Республик, Генеральному секретарю ЦК КПСС тов. Горбачеву М.С. // Социалистическая Осетия. 1991. № 29. 8 февраля.

23. Тбилиси, Гостелерадио Республики Грузия. Коммунистам Грузии // Социалистическая Осетия. 1991. № 29. 8 фревраля.

24. Прекратить экономическую блокаду // Социалистическая Осетия. 1991. 15 февраля;

25. Беспокойство за братьев // Растдзинад. 1991. $16 \mathrm{ceн-}$ тября

26. Нестеренко А. Не повторять чужих ошибок: [Северная Ирландия - Северная Осетия: дорогой миротворчества] // Соц. Осетия. 1991. 26 фревраля.

27. Ричард Нельсон Фрай. Южная Осетия глазами американиа // Северная Осетия. 1991. 29 ноября.

28. Чрезвычайный съезд осетинского народа. Защитникам Цхинвали, всем жителям осажденной Южной Осетии // Северная Осетия. 1991. 21 декабря.

29. Обращение к народам Северного Кавказа - членам Конфедерации горских народов // Северная Осетия. 1991. 21 декабря.

30. Съезд осетинского народа. Президенту РСФСР Б.Н. Ельцину // Северная Осетия. 1991. 24 декабря.

31. В Организацию Объединенных наций, Главам государств и правительств. Обращение Чрезвычайного съезда осетинского народа // Северная Осетия. 1991. 24 декабря. 32. В Верховный Совет РСФСР: обращение Чрезвычайного съезда осетинского народа // Северная Осетия. 1991. 24 декабря

33. Участники республиканского семинара-совещания секретарей первичных партийных организаций Северной Осетии: Президенту СССР, генсеку ЦК КПСС тов. Горбачеву М.С. // Социалистическая Осетия. 1991. 8 февраля.

34. Дзантиев А. Власть тьмы // Южная Осетия: и кровь, и пепел... - Владикавказ: "Чертановская типография» МГПО, 1991. С. 6. 


\title{
THE GEORGIAN-OSSETIAN CONFLICT OF 1989-1992 IN THE CONTEXT OF EVOLUTIONARY PROCESSES IN THE MEDIA OF THE REPUBLIC OF NORTH OSSETIA-ALANIA
}

\author{
Kh.G. Kodalaeva
}

Head of the Chair of Journalism of the South Ossetian State University after A.A.Tibilov.

Abstract. This article aims to analyze Georgian-Ossetian conflict of 1989-1992 in the context of the evolutionary processes in the mass media of the Republic of North Ossetia-Alania. Within the specified period it examines the most informative publications on the pages of the republican press is analyzed ("Severnaya Ossetia» - "North Ossetia», "Rastdzinad» - "The Truth», "Slovo» - "The Word») where the causes and essence of the Georgian national-extremists circles' criminal acts are demonstrated. The article suggests mechanisms for this complex issue studying on the materials of local press.

Keywords: Georgian-Ossetian conflict, evolutionary processes in the mass media, ethno-political processes, information blackout, religious factor, North Ossetian press.

\section{REFERENCES}

1. Avksent'yev V.A. Etnicheskaya konfliktologiya: v poiskakh nauchnoy paradigmy. - Stavropol', 2001.

2. Babkin I.O. Fenomen etnicheskogo separatizma: Avtoref. diss. ... kand.polit, nauk. - Stavropol', 2001.

3. Sanakoev I.B. Istoki i faktory evolyutsii gruzino-osetinskogo konflikta (1989-1992 gg.). - Vladikavkaz: Izdatel'skopoligraficheskoe predpriyatie im. V.A. Gassieva, 2004. 160 s.

4. Sizyy F. Dom oknami na voynu // Komsomol'skaya pravda. 1991. 31 yanvarya.

5. OchirovaT., Dzhioshvili D. Bratoubiystvo // Literaturnaya Rossiya. 1991. 8 fevralya.

6. Glebova Ekaterina. Shal'nye puli snayperov // Moskovskiy komsomolets. 1991. 15-16 fevralya.

7. Pral"nikov A. Tskhinvali s Beyrutskim aktsentom // Megapolis-ekspress. 1991. 31 yanvarya.

8. Astrov V. Noch'v Tskhinvali // Megapolis-kontinent. 1991. № 8. Fevral'-mart.

9. Dzidzoev V.D. Osetiya $v$ epokhu bol'shikh potryaseniy i peremen (istoricheskiy i politiko-pravovoy analiz postsovetskoy istorii). - Vladikavkaz, 2010.

10. Dzidzoev V.D. Problemy sovetskogo natsional'no-gosudarstvennogo stroitel'stva v Osetii i postsovetskie itogi (politikopravovoy analiz). - Vladikavkaz, 2011.

11. Dzidzoev V.D. Bor'ba yugoosetinskogo naroda za natsional'noe samoopredelenie. 1917-1990 gg. - Vladikavkaz, 2011.

12. Dzidzoev V.D., Dzugaev K.G. Yuzhnaya Osetiya v retrospektive gruzino-osetinskikh otnosheniy. - Tskhinval, 2007.

13. Abaev V.I. TragediyaYuzhnoy Osetii: bespredel genotsida. - Tskhinval, 2007.

14. Dzarasov S. Anatomiya bedy // Golos (Moskva). 1991. № 15. Aprel'.

15. Chochieva Zh. Bol'shoy kavkazskiy dom // Zavtra. 1997. № 34. S. 3.

16. Dzhikaev X. Pozvol'te vozrazit'. DIKost': [Nash otvet vitse-prezidentu SShA Diku Cheyni] // Pul'sOsetii. 2006. № 33. Avgust.

17. Tsagolov K. Natsional'nyy meshchanin s ruzh'yem // Rabochaya tribuna (Moskva). 1991. 12 marta.

18. Oleynik B. Etot konflikt opalyaet vsyu stranu: [Beseda posle vozvrashcheniya iz Yuzhnoy Osetii] // Sovetskaya Rossiya. 1991. 26 fevralya.

19. Nemchenko G. Tsvetyzla: [Slovo pisatelya] // Pravda. 1991. 16 aprelya.

20. Yuzhnaya Osetiya glazami zhurnalistov (1991-1992) / Sost. Aleksey Margiev. - Tskhinval: Izdatel'stvo «lryston», 2001. $344 \mathrm{~s}$.

21. Yuzhnaya Osetiya glazami zhurnalistov (1991-1992) / Sost. Aleksey Margiev. Predislovie B. Kharebova. - Tskhinval: Izdatel'stvo «Iryston», 2001.

22. Prezidentu Soyuza Sovetskikh Sotsialisticheskikh Respublik, General'nomu sekretaryu TsK KPSS tov. Gorbachevu M.S. // Sotsialisticheskaya Osetiya. 1991. № 29. 8 fevralya.

23. Tbilisi, Gosteleradio Respubliki Gruziya. Kommunistam Gruzii // Sotsialisticheskaya Osetiya. 1991. № 29. 8 fevralya.

24. Prekratit' ekonomicheskuyu blokadu // Sotsialisticheskaya Osetiya. 1991. 15 fevralya;

25. Bespokoystvo za brat'yev // Rastdzinad. 1991. 16 sentyabrya.

26. Nesterenko A. Ne povtoryat' chuzhikh oshibok: [Severnaya Irlandiya - Severnaya Osetiya: dorogoy mirotvorchestva] // Sots. Osetiya. 1991. 26 fevralya.

27. Richard Nel'son Fray. Yuzhnaya Osetiya glazami amerikantsa // Severnaya Osetiya. 1991. 29 noyabrya.

28. Chrezvychaynyy s"ezd osetinskogo naroda. ZashchitnikamTskhinvali, vsem zhitelyam osazhdennoy Yuzhnoy Osetii // Severnaya Osetiya. 1991. 21 dekabrya.

29. Obrashchenie k narodam Severnogo Kavkaza - chlenam Konfederatsii gorskikh narodov // Severnaya Osetiya. 1991.21 dekabrya.

30. S"ezd osetinskogo naroda. Prezidentu RSFSR B.N. El'tsinu // Severnaya Osetiya. 1991. 24 dekabrya.

31. V Organizatsiyu Ob"edinennykh natsiy, Glavam gosudarstv i pravitel'stv. Obrashchenie Chrezvychaynogo s"ezda osetinskogo naroda // Severnaya Osetiya. 1991. 24 dekabrya.

32. V Verkhovnyy Sovet RSFSR: obrashchenie Chrezvychaynogo s"ezda osetinskogo naroda // Severnaya Osetiya. 1991. 24 dekabrya.

33. Uchastniki respublikanskogo seminara-soveshchaniya sekretarey pervichnykh partiynykh organizatsiy Severnoy Osetii: Prezidentu SSSR, genseku TsK KPSS tov. Gorbachevu M.S. // Sotsialisticheskaya Osetiya. 1991. 8 fevralya.

34. Dzantiev A. Vlast' t'my // Yuzhnaya Osetiya: i krov', i pepel... - Vladikavkaz: "Chertanovskaya tipografiya» MGPO, 1991. S. 6 . 